\title{
Factors Involved in Stress Corrosion Cracking of Tubes from a Nuclear Power Plant Feed water Heater
}

\author{
MANUELA FULGER*, DUMITRA LUCAN, MARIA MIHALACHE, LUCIAN VELCIU \\ Institute for Nuclear Research, 1 Campului Str., 110392, Pitesti, Romania
}

\begin{abstract}
This study has been carried out to identify the operating factors involved in the failure of two tubes made of 304 stainless steel removed from a high pressure feed water heater working in a nuclear power plant. The samples cut from tubes have been analyzed by different methods: visual examination, optical (metallographic) microscopy, scanning electron microscopy, and energy dispersive $X$-ray spectroscopy. Following analyses, on the surface of tubes was highlighted the presence of many pits in which cracks have started. Inside the pits, impurities of the type S, Cl, K, Ca were detected too. The branched cracks most likely have occurred as a result of precipitation of small amounts of chlorides deposited and concentrated on the surface of the tubes over a long period of operation. The stresses that favored this type of corrosion cracking were both residual stresses and stresses occurring at the torsion and bending of the tubes, while the high water temperature from feed heater was also a favorable factor for corrosion. The final conclusion was that the tubes failed by a chloride induced stress corrosion cracking mechanism.
\end{abstract}

Keywords: 304 stainless steel, chloride stress corrosion cracking, NPP heater, SEM, EDS

In a nuclear power plant (NPP) the feedwater heating systems normally operate as counterflow heat exchangers which use extraction steam from turbines to preheat the feedwater for steam generators. The most common configuration of feedwater heater is a shell and tubing with the water flowing inside the tubes and steam condensing outside. Malfunctioning of feedwater heaters can affect power plant efficiency by increasing heat rate and/or decreasing electricity generation capacity. These heaters can fail due to vibration, flashing of drain flow, inadequate level control, steam impingement, erosion, and/or corrosion. There are some areas more exposed to the failure risk, as outside zone of tubes, steam entry zone, condensing zone, and drain cooler [1].

During the working life of a feedwater heater, the tubes can fail due to the operational characteristics and their consequences, as variation of flow rate, water chemistry, uniform corrosion, erosion, localized corrosion on the tube surface, intergranular corrosion, galvanic corrosion and corrosion from oxygen formation. Also, in a feedwater heater tube, failures can result from poor quality control of tubing during the manufacturing process. The 304 stainless steel is a highly reliable and commonly alloy used for tubes in many heat exchangers [2]. But it is also well known to be susceptible to stress corrosion cracking in the presence of chlorides and oxygen [3].

In general, the stress corrosion cracking (SCC) is a form of slow crack growth that occurs when a susceptible alloy is stressed due to various causes [4]. Literature [3-8] shows that the susceptibility of austenitic stainless steels to this kind of corrosion, especially chloride stress corrosion cracking (CSCC), depends on a combination of the following factors: environmental variables (chlorides concentration, temperature, $\mathrm{pH}$, oxygen), stress level (residual stresses or service stresses), surface finishing and the metallurgical condition of the steel. Generally, this type of corrosion is initiated from sites of localized corrosion (pitting or crevice). If initiation of cracks is mostly dependent on the chloride concentration and less by temperature, the propagation is widely affected by cyclical temperatures changes. The combined effects of stress,

* email: manuela.fulger@nuclear.ro, Phone:0248 213400 ext 249 environment and material properties are root causes of initiation and propagation of cracks, which can be intergranular or transgranular. In a chloride environment the transgranular cracking is the most common $[4,9]$. A review of corrosion studies regarding SCC in water shows that most studies are regarding to relatively low temperatures and pressures [10,11], but only a few refer to corrosion at high values of these parameters [12].

This study has been carried out to investigate the CSCC mechanism developed on two tubes removed from a NPP high pressure feedwater heater after 15 years of operation at $147-190{ }^{\circ} \mathrm{C}$ temperatures and $15-90$ bar pressures.

\section{Experimental part}

The both analyzed tubes removed from high pressure (HP) feedwater heater are made of SA 213 TP 304 stainless steel. Their operating parameters are the followings: $\sim 190$ ${ }^{\circ} \mathrm{C}$ inlet temperature, $\sim 151^{\circ} \mathrm{C}$ outlet temperature and 15 bar pressure for steam and condense which flow outerside of tubes, and $\sim 147^{\circ} \mathrm{C}$ inlet temperature, $\sim 167{ }^{\circ} \mathrm{C}$ outlet temperature and 90 bar pressure for demineralized water which flows through the tubes. To investigate the failure mechanism of tubes the visual inspection, metallographic and SEM microscopy as well as elemental analysis have been performed. Visual inspection of the degraded components is a non-destructive examination of the failure which precedes any mechanical testing or any metallurgical examination. Visual examination completed with photographic records for comparison, remains the cornerstone of any failure examination [13-15]. The metallography analysis is a macroscopic examination of the samples surface followed by a microscale examination of etched or unetched material as well as transverse and longitudinal cross sections. For this analysis has been used a metallographic microscope OLYMPUS GX 71 type. For a detailed analysis ( secondary cracks, abnormalities, origin of fracture and direction of the crack growth) a TESCAN VEGA II LMU scanning electron microscope operating up to $30 \mathrm{kV}$ has been used. The chemical (elemental) analysis of the corrosion products composition has been performed using the technique in points with an energy dispersive Xray spectroscopy (EDS) device. 


\section{Results and discussions}

Using the visual inspection made on the entire length of both tubes ( $T_{1}$ and $\left.T_{2}\right)$ it has been noticed that on the tube surface there were marks resulted from friction with the tubes supports and also scratches probably from manipulation at removing (Figure 1). Moreover, on the one side of both tubes red oxides and hard deposits have been observed, formed over a black oxide (magnetite), while on the reverse side there is a magnetite layer maintained almost intact (Figure 1). These mean that the faces of tubes were degraded being subjected to small droplets of water which eroded tubes. On the reverse sides, just dry steam was in contact with the tubes, therefore it may be the aggressive agent. For an easier manipulation in the further analyses after visual examination, the tubes have been cut in pieces of $2 \mathrm{~cm}$ of length. By metallographic analysis of the tubes at a low magnification $(\times 40)$ the corrosion products have been observed, covering the most outside surface while on the inside, only an adherent oxide layer was detected (Figure 2).

For the following analysis, the surfaces of samples were brushed to remove the hard deposits. After brushing the oxides, there were observed on the entire surface of tubes pits with different sizes (Figure 3). This means that, under the corosion products layer, the impurities from water have been concentrated and in time these can lead to pitting corrosion. After complete removing of oxides using an acidic aqueous solution ( $15 \% \mathrm{HNO}_{3}, 3 \% \mathrm{HF}, 3 \% \mathrm{HCl}$ ) for 30 seconds at temperature of $75^{\circ} \mathrm{C}$, on the samples surface have been relieved many pitts and longitudinal cracks, as in Figure 4

A microstructural examination has been performed on the samples after using electrochemical etching. Microscopic (SEM) examination relieved that the base material has an austenitic phase grain structure which is

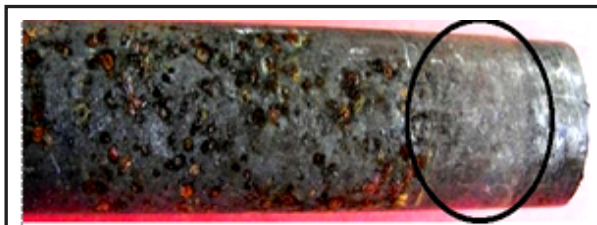

Degraded outside of tube $T_{1}$

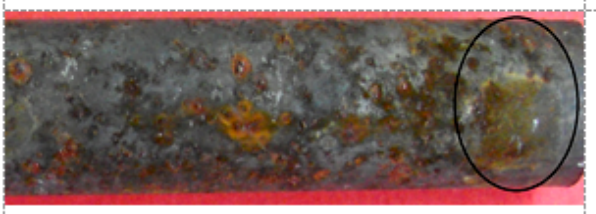

Degraded outside of tube $T_{2}$

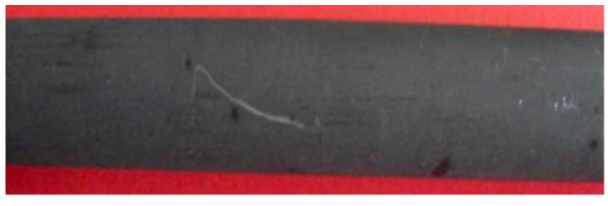

Reversed side of tube $\mathrm{T}_{1}$

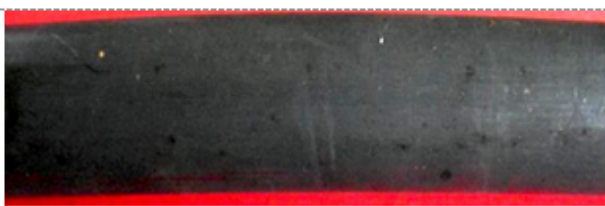

Reversed side of tube $\mathrm{T}_{2}$
Fig. 1. Optical microscopy aspect of $T_{1}$ and $T_{2}$ tubes surfaces
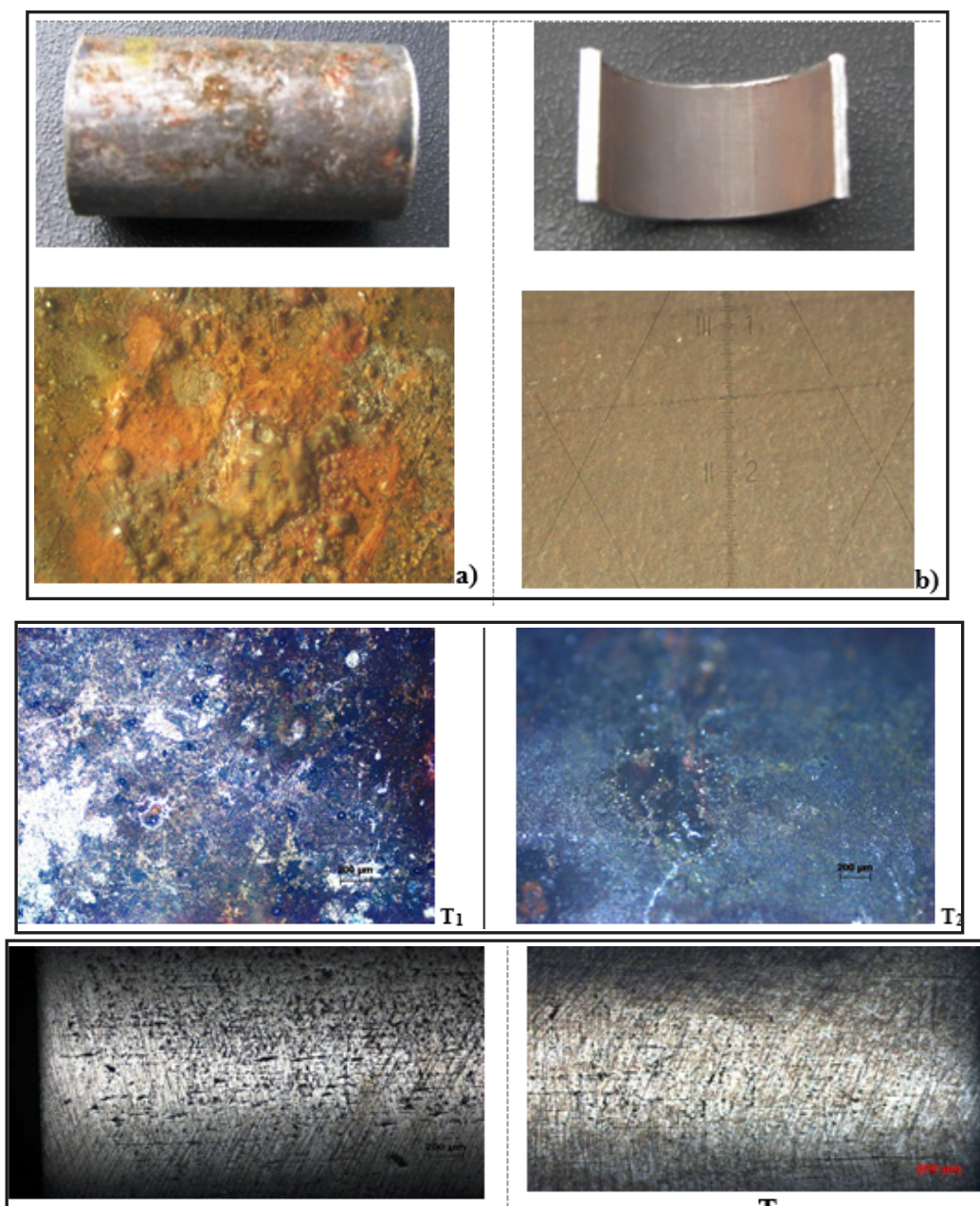

$T_{1}$

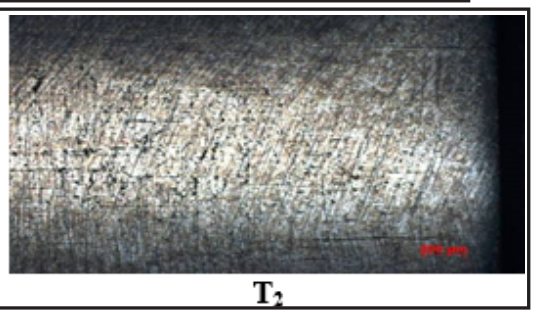

$\mathbf{T}_{2}$
Fig. 2 (a) Red oxydes and hard corrosion deposits visualized on outside surface and (b) an adherent oxide layer on the inside surface (magnification x40)
Fig. 3. Outside surfaces after oxides brushing (magnification $\times 50$ )
Fig. 4. Pits and longitudinal cracks on the tubes surfaces after descaling (x50) 

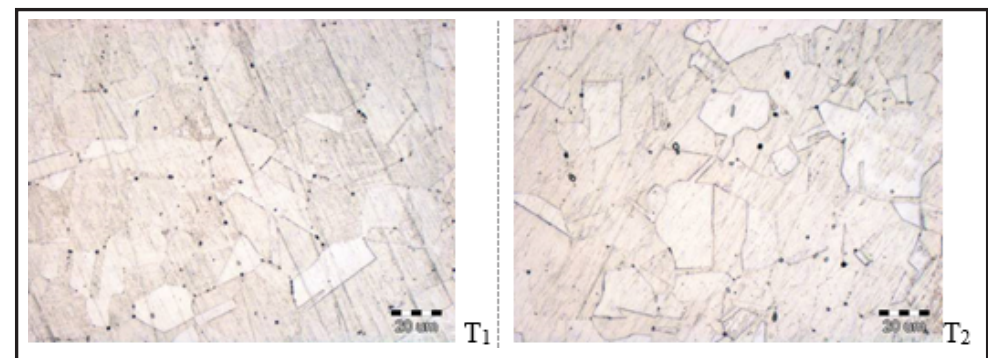

characteristic to 304 stainless steel (Figure 5). There are not visible carbides at grain boundaries butmany inclusions can be observed, formed probably in casting process of the steel. The SEM analysis of the tubes surfaces also revealed the presence of a black oxide film (magnetite) over which there are distributed needle shaped crystals (Figure 6). Another SEM images, achieved into pits filled with oxides, highlighted the presence of the same needle shaped crystals (Figure 7). The chemical composition of the oxides formed on the outside surface was determined from the EDS spectrum obtained by analysis in points on the tubes surface. This elemental analysis revealed that the oxides contain iron, chromium, nickel, oxygen and

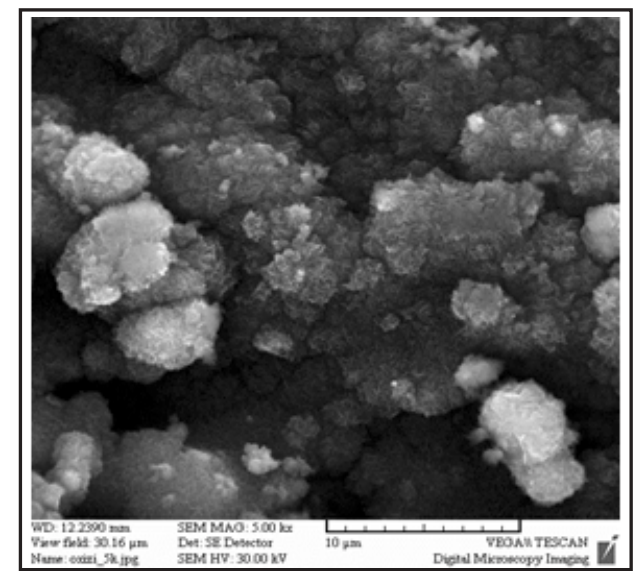

Fig. 6. SEM image of outer oxide layer with needle shape crystals inclusions (x5000)
Fig. 5. Austenitic microstructure of $T_{1}$ and $T_{2}$ samples (x500) some impurities, such as chlorine, sulfur, calcium, and potassium (Figure 8). Table 1 shows that the concentration of impurities in examined points is quite high. Accordingly, a conclusion may be that the needle shaped crystals detected by SEM are crystals of chlorides $\left(\mathrm{CaCl}_{2}\right.$ or $\left.\mathrm{KCl}\right)$. Detection of these impurities demonstrates that inside of the preheater the unpurified water remains stationary, thus allowing accumulation and concentration of salt impurities on the hot surfaces of the tubes. The unpurified water can come from a damaged condenser which usualy is cooled with raw water. The supposition that the impurities from steam could reach up to the base metal can be supported

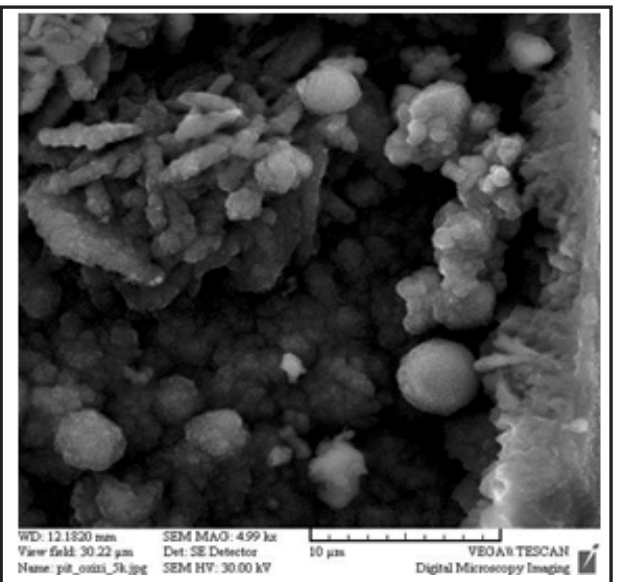

Fig. 7. SEM image of the needle shape crystals inside of pits ( $x 5000)$

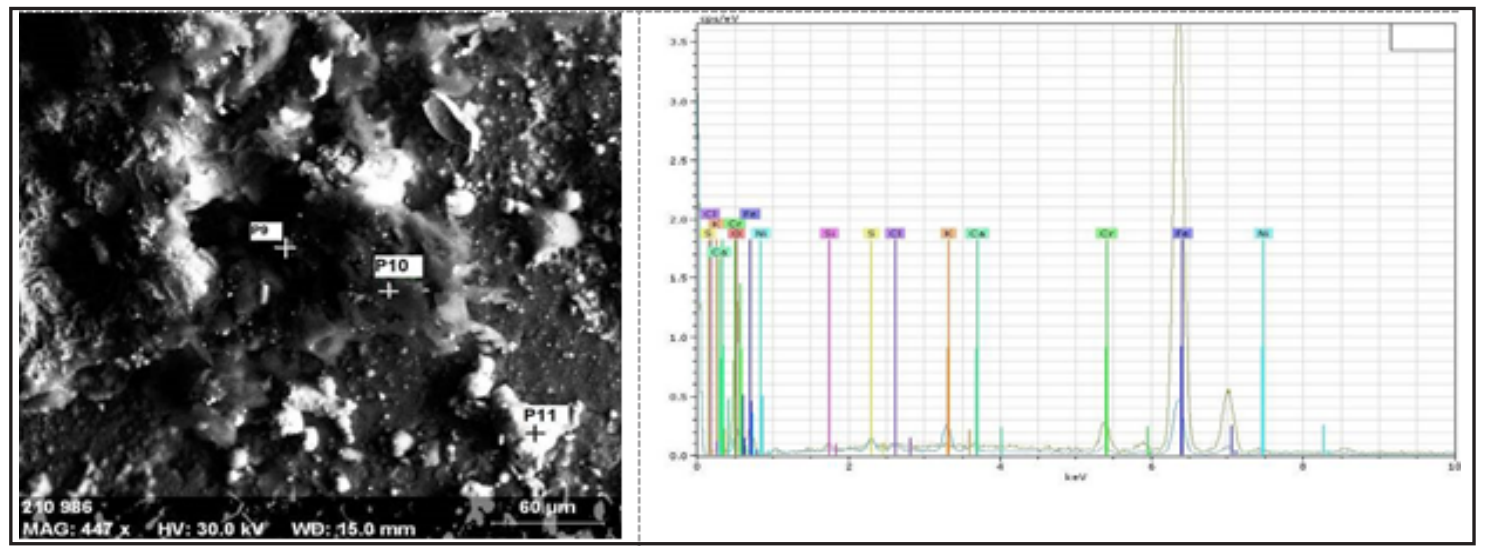

Fig. 8. EDS analysis in points showing the presence of impurities $(\mathrm{Cl}, \mathrm{Ca}, \mathrm{S}, \mathrm{K})$ in oxides (P10,P11) and inside of pit (P9)

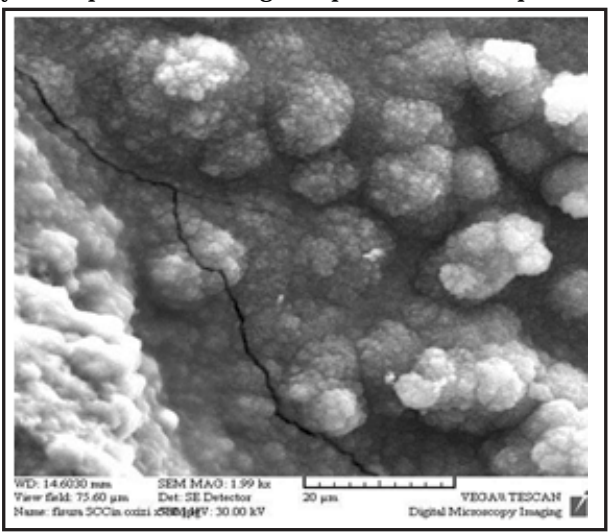

Fig. 9. SEM image of the cracks in the oxide (x2000) 
Table 1

CONCENTRATION OF ELEMENTS IDENTIFIED BY EDS ON THE TUBES SURFACE

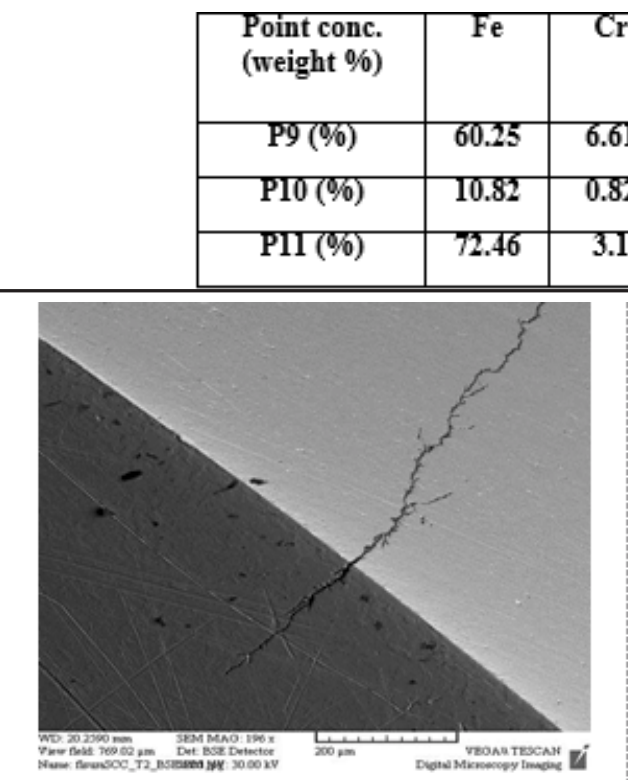

a)

\begin{tabular}{|c|c|c|c|c|c|c|c|}
\hline $\mathrm{r}$ & $\mathrm{Ni}$ & $\mathrm{Si}$ & $\mathrm{S}$ & $\mathrm{Ca}$ & $\mathrm{Cl}$ & $\mathrm{K}$ & $\mathrm{O}$ \\
& & & & & & \\
\hline .82 & 0.44 & 0.35 & 0.81 & 0.16 & 0.43 & 1.92 & 84.25 \\
\hline .1 & 1.48 & 1.32 & 1.12 & 0.45 & 0.53 & 0.4 & 19.14 \\
\hline
\end{tabular}

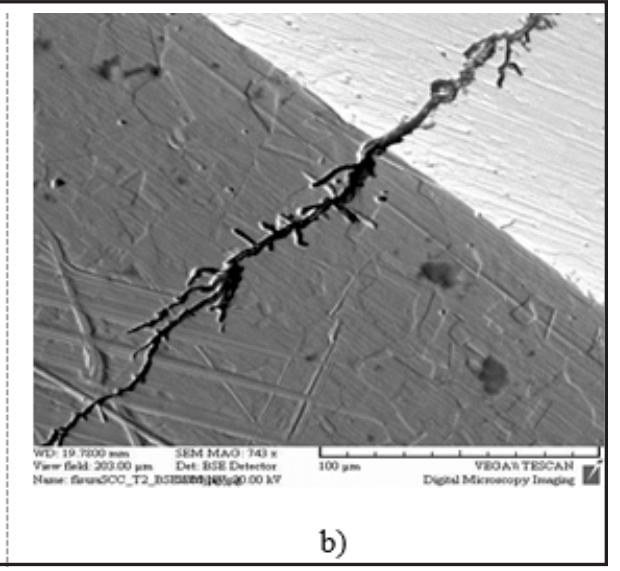

Fig. 10. Secondary electron SEM image of longitudinal crack identified on the tube's surface a) (x200), b) $(x 700)$

than $60^{\circ} \mathrm{C}$ and the presence of oxygen. For feedwater heaters this would be in the form of dissolved oxygen as a result of air in leakage through the surface condenser $[7,15]$

In the next step of analysis, a transverse cross section through the longitudinal cracks has been performed. Figure 10 shows secondary electrons SEM image of one longitudinal crack which was also identified previously through optical microscopy on the outside surface of tube $T_{2}$. Note that the crack is branched, and passes both at grain boundary and through the grains. The crack has been initiated from a surface pit and propagated in the longitudinal direction and to the inside, close to half of wall thickness. This type of branched crack usually occurs on 304 stainless steel when chlorides are present in operating water [5]. The chlorides were detected by SEM/EDS on the surface of tubes analyzed, so the conclusion is that tube degradation can be related to chloride stress corrosion cracking (CSCC).

The cracks most likely occurred as a result of very small amounts of chlorides deposited and concentrated on the surface of the tubes over a long period of operation. Chlorides salts are coming from the condenser which probably has some problems at the tubes and allows the raw water (used for cooling) to arrive as condense into the high pressure feedwater heater. Degradation by corrosion occurred in the condensing zone on the outside of tubes as a result of the relatively high steam velocities (high flow rate of steam) in this area where the tube wall temperature is cycled. Generally, when a unit ramps down, the tubes remain relatively hot, drying the outside of tubes after they have been again in a wet condensing area. This drying, then wetting and also drying cycle, will tend to concentrate minors amounts of impurities (as chlorides) on the tube's surface [5].

Chlorides identified byEDS, indicated that this chloride stress corrosion cracking mechanism could exist. Chlorides enter into the feedwater system when there are condenser tube failures or problems with the demineralizer. The stress level includes residual stresses or service stresses. Residual stress could occur from a manufacturing process or during installation. Service stress is caused by an expansion stress, hoop stress, or bending stress. A susceptible environment involves temperatures greater

\section{Conclusions}

This study emphasized the degradation mechanism of plugged tubes removed from a NPP high pressure feedwater heater, after 15 years of operation. Analysis of the tube sections indicated that the degradation was related to chloride stress corrosion cracking (CSCC) according to the following scenario. First, the corrosion products are deposited on the tubes surface producing crevices where the fluid was stagnant, leading in time to impurities concentration. Then, the impurities containing aggressive ions (chloride, sulfur, potasium, mainly identified by EDS) change the $\mathrm{pH}$ of environment inside of crevices, thus occuring a localized corrosion (pitting). Due to the operating stress, residual stress and lower chemical resistance of 304 stainless steel at chloride ions, the branched cracks are initiated from pits and penetrated the tubes wall leading to leaks.

After this analysis, some useful actions resulted, that need to be followed to avoid further failures:

-identification of any leaks from condensers to avoid entry of aggressive environment;

-a rigorous chemical control of environment to prevent local concentration of aggressive species in the areas with restricted circulation;

-regularly inspections of tubes, especially in problem areas, as in the cooler drain, near the inlet of steam around plugging tubes and random;

-residual stress elimination by heat treatments applied to tubes before use;

-a rigorous control of tubes surfaces before the installation for elimination of the surface defects.

\section{References}

1. BEREZNAI, G., HARVEL, G., Introduction to CANDU Systems and Operation, University of Ontario Institute of Technology, Oshawa, Canada, 2011

2. FULGER, M, RADULESCU, M, LUCAN, D., DEMETRESCU, I., The corrosion kinetics of 304L stainless steel, Incoloy 800 and SA 516 
carbon steel in the secondary circuit of the nuclear steam generator, Rev. Chim. (Bucharest), 55, no.3, 2004, p. 163-168

3. SHOH, T., LU, Z., PENG, Q., Factors stress affecting corrosion cracking (SCC) and fundamental mechanistic understanding of stainless steels, in: Stress Corrosion Cracking: Theory and Practice, 2011, Raja V.S. and Shoji T. Editors, Woodhead Publishing Ltd, Cambridge, UK, p. 245-272

4. AL-BALDAWI, R.A., ABDULLAH M.N., Tube damage mechanism and analysis in feedwater heaters, Journal of Engineering and Development, 16, No.1, 2012, p.261-272

5. PARROTT, R., PITTS, H., Chloride stress corrosion cracking in austenitic stainless steel, RR902 Research Report, HSE Books, London, 2011

6. XIE, Y., ZHANG, J., Chloride-induced stress corrosion cracking of used nuclear fuel welded stainless steel canisters: A review, Journal of Nuclear Materials, 466, 2015, p. 85-93

7. SIVANATHAN, P., ISMAIL, M.C., ENG, K.K., Chloride stress corrosion cracking (CSCC) of austenitic stainless steel under thermal insulation: Case study analysis, ARPN J ournal of Engineering and Applied Sciences, 11, No. 24, 2016, p. 14239-14243

8. HSU, C.H., CHEN, T.C., HUANG, R.T., TSAY, L.W., Stress corrosion cracking susceptibility of $304 \mathrm{~L}$ substrate and $308 \mathrm{~L}$ weld metal exposed to a salt spray, Materials, 10, 2017, Paper 187 (14 pages)

9. SPENCER, D.T., EDWARDS, M.R., WENMAN, M.R., TSITSIOS, C., SCATIGNO, G.G., CHARD-TUCKEY, P.R., The initiation and propagation of chloride-induced transgranular stress-corrosion cracking (TGSCC) of $304 \mathrm{~L}$ austenitic stainless steel under atmospheric conditions, Corrosion Science, $\mathbf{8 8}$, No. 11, 2014. p. 76-88
10. BRUEMMER, S.M., JONES, R., DIVINE, J., J OHNSON, A., Evaluating the intergranular SCC resistance of sensitized type 304 stainless steel in low temperature water environments, in: ASTM STP 821 Environment Sensitive Fracture: Evaluation and Comparison of Test Methods, Dean S.W., Pugh E.N. and Ugiansky G.M., Editors. 1984, ASTM International, West Conshohocken, PA, p. 256-270

11. CONGLETON, J., SUI, G., The stress corrosion cracking of heavily sensitised type 316 stainless steel in water in the temperature range 50-100 ํ. C, Corrosion Science, 33, No.11, 1992, p. 1691-1717

12. ANDRESEN, P., MORRA, M.M., IGSCC of non-sensitized stainless steels in high temperature water, Journal of Nuclear Materials, 383, No. 1, 2008, p. 97-111

13. ZAMANZADEH, M., LARKIN, E.S., BAYER, G.T., LINHART, W.J ., Failure analysis and investigation methods for boiler tube failures, Paper No. 7450, Waterside Boiler Tube Failure Symposium, CORROSION 2007, 11-15 March 2007, Nashville, Tennessee

14. MALIK, A.M., ANDIJANI,I., MOBIN, M., AL-MUAILI, F., AL-HAJRI, M., Corrosion of boiler tubes some case studies, Proc. of SWCC Aquired Experience Symposium, 2005, Jedah, p.739-763

15. FULGER, M., MIHALACHE, M., VELCIU, L., VITELARU, I., Corrosion mechanisms of tubes from the CANDU high pressure feed water heaters, Proc. of NUCLEAR 2013, the 6th Annual Int. Conf. on Sustainable Development Through Nuclear Research and Education. Part 2/3, 2224 May 2013, Pitesti, Romania, p. 125-133

Manuscript received: 17.08 .2018 